\title{
AC 2009-1257: IMPACT OF INTEGRATION OF UNDERGRADUATE STUDENTS IN AN ENGINEERING RESEARCH LABORATORY: A CASE STUDY
}

\section{Adam Ekenseair, University of Texas, Austin}

Adam Ekenseair is a doctoral student in Chemical Engineering at the University of Texas at Austin. He received his B.S. in Chemical Engineering from the University of Arkansas at Fayetteville in May 2005. Currently he is working in the laboratory of Dr. Nicholas Peppas on "A Fundamental Investigation of Non-Fickian Penetrant Transport in Glassy Polymers." Adam is a Department of Defense (NDSEG) Fellow and a National Science Foundation (NSF-GREP) Fellow. He is also active in the American Institute of Chemical Engineering, the American Physical Society, and the Materials Research Society. Adam has presented 5 papers at major conferences and has 1 refereed publication.

\section{Carolyn Bayer, University of Texas, Austin}

Carolyn Bayer is a graduate research fellow in Biomedical Engineering at the University of Texas at Austin. She received a B.S. degree in Electrical Engineering from Case Western Reserve University in May 1998. After graduation, she was employed at Motorola for the development of DNA microarrays within the Life Sciences Division (now part of GE Medical). Her experience at Motorola led to a position as a senior engineer at Neogenesis (now part of Schering-Plough) in Cambridge, MA. She returned to school in the fall of 2005 to pursue a PhD in Biomedical Engineering, working with Dr. Nicholas A. Peppas at the University of Texas at Austin as an NSF-IGERT fellow. Her research explores the biosensing properties of conductive and recognitive hydrogels. She has authored 1 refereed publication in press, and 1 refereed publication in submission, in addition to conference presentations and proceedings.

\section{Margaret Phillips, University of Texas, Austin}

Margaret A. Phillips is a doctoral student in Biomedical Engineering at The University of Texas at Austin. Margaret graduated magna cum laude from Saint Louis University in 2006 where she received her undergraduate degree in Biomedical Engineering. An NSF-IGERT fellow, she is working with Dr. Nicholas Peppas to develop carbohydrate-decorated hydrogels for oral protein delivery. She is currently serving a two year term as the National Student President of the Society For Biomaterials. 


\title{
Impact of Integration of Undergraduate Students in an Engineering Research Laboratory: A Case Study
}

\begin{abstract}
Participation in undergraduate research projects in engineering can result in lasting benefits for the education and careers of both the undergraduate students and their graduate student mentors and supervising professors. This conclusion is supported by the results of surveys and interviews with a selection of the 526 undergraduate students who have participated in undergraduate research projects in our laboratory over the past 30 years, as well as their graduate student mentors. In addition, analogous data from the chemical and biomedical engineering departments at our institution demonstrate the beneficial long-term impact of undergraduate research on an engineer's career and pursuit of higher education. Furthermore, it is shown through both comprehensive data and specific examples that the research performed and the personal relationships developed have lasting benefits to the careers of the graduate mentors and the supervising professors.
\end{abstract}

Key elements to implementing a significant and successful undergraduate research program at the laboratory, department, and university level have been identified from statistical data and personal experiences. Additionally, the impact of the supporting infrastructure at the departmental and university levels on the success of undergraduate research programs was established. Specific methods for attracting, retaining, and enhancing excellent undergraduate researchers while maximizing their productivity are illustrated with this data.

\section{Introduction}

Involving undergraduate researchers in engineering research has been a longstanding tradition and strength of the laboratory of Nicholas A. Peppas both at The University of Texas at Austin (UT) and Purdue University. In this paper, some of the strengths and outcomes of the 33 year tradition are summarized within the broader context of undergraduate research at researchoriented higher education institutions where the Peppas laboratory has made its home.

Research-oriented higher education institutions, including The University of Texas at Austin, have two primary goals - to produce high quality research, and to produce educated graduates. Doctorate-granting universities, which award more than 20 doctoral degrees annually, are classified as research universities with very high or high research activity by the Carnegie Commission on Higher Education ${ }^{1}$, based on research and development expenditures, the number of science and engineering research staff, and the number of doctoral degrees granted in specific fields of study. Historically, the conflict between baccalaureate studies and research activities arises from the German educational model of the $19^{\text {th }}$ century, after which American research institutions were designed - research was the ultimate goal of the institution, while education remained a secondary activity. Undergraduate education was intentionally separated from the research activities of the university, and the recruitment and promotion of faculty is dependent primarily upon their research progress. Research institutions therefore have a large number of world renowned research professors, which presumably enhances the education of the 
undergraduate students, but in practice, undergraduate students often lack access to these exceptional research scientists ${ }^{2}$.

However, since the 1960s, it has been recognized that maintaining this separation ultimately benefits neither the research faculty nor the undergraduate students. Notable reports, such as the Boyer Commission report in 1998, have described this conflict between undergraduate education and research and suggested ways to improve the undergraduate educational experience by incorporating research activities. The benefits of integrating undergraduate education and research include the ability to provide an educational experience unique to research universities, the generation of new research ideas through interaction with less experienced students, and the improvement of the graduate education through teaching and research integration. A specific recommendation in the Boyer Commission report is the incorporation of research-based learning into undergraduate education. Mechanisms to accomplish this include involving undergraduates in research as soon as the freshman year, providing a research mentor for every student, providing opportunities for the students to learn how to communicate their research results effectively, and the inclusion of internship opportunities. The publication of this report resulted in the creation of programs to address the integration of undergraduate education and research ${ }^{2}$.

Evidence exists that these approaches towards the inclusion of undergraduate research do improve the quality of undergraduate education. At universities with established undergraduate research programs, studies have shown that participating students view these learning experiences positively and demonstrate improved research skills ${ }^{3,4}$. A study of university alumni demonstrated significant improvements in self assessment between those who had participated in an undergraduate research program, and those who had not performed research, including their ability to speak effectively, acquire information on their own, leadership, understanding of scientific findings, critical analysis of literature, definition of career goals, and development of intellectual curiosity. In addition, several studies have determined that undergraduate research participants are significantly more likely to pursue graduate education ${ }^{3,5,6}$.

In light of the more recent emphasis on the involvement of undergraduates in research, the purpose of this paper is to highlight the effectiveness of the undergraduate research program in the laboratory of Nicholas A. Peppas and to study the impact that has been made not only on the education and careers of the undergraduate participants but also on their graduate student mentors. To this end, a selection of former undergraduate and graduate students have been surveyed on the direct impact of their research experience in our laboratory, with a particular emphasis on the importance of the program in influencing a student's decision to seek a higher degree. In addition, an analogous study was conducted by surveying current and former undergraduate and current graduate students in engineering disciplines at the University of Texas at Austin who have not been associated with our laboratory. Finally, available supporting programs at the departmental and university level are described and their impact on the success of our undergraduate research program is assessed.

\section{Laboratory Background and Program Methodology}

The laboratory of Nicholas A. Peppas has long sought to enhance the quality of undergraduate education by incorporating chemical and biomedical engineering undergraduates in its research 
efforts, inspired in large part by his experience supervising four undergraduate researchers while pursuing his Doctorate as part of MIT's Undergraduate Research Opportunities Program ${ }^{7-8}$. Over the course of 33 years at both Purdue University $(1976$ - 2002) and the University of Texas at Austin (2003 - 2009), 526 undergraduate students have participated in research projects either under the direct supervision of Professor Peppas or under the supervision of an appointed graduate student mentor. In developing and maintaining this program, we have coincidentally followed many of the recommendations of the Boyer Commission including providing every undergraduate participant with a direct research mentor and a well-defined project. In addition, students have been both encouraged to utilize and recruited through the supporting programs at the departmental and university level. Indeed, it is our contention that the level of institutional support at our university has been a key catalyst in broadening the educational experience of the participants in this undergraduate research program.

The success of an undergraduate research program at any level begins with recruitment and program awareness. Most undergraduate students complete their degrees with only a marginal awareness that research occurs in their department and even less understanding of what individual professors are working to accomplish in their laboratories. It is thus important to make undergraduate research more accessible to students. In our laboratory, this is typically accomplished through briefly discussing research efforts in the classroom and through undergraduate advising. By informing undergraduates of the specific possibilities and benefits (course credit, experience, etc.) of laboratory research participation, we obtain a greater number of highly interested students. Those undergraduates who express their interest and seem like a good match for the laboratory are recruited to work directly with the professor or are introduced to possible graduate student mentors to discuss specific research projects. Furthermore, it has been our general conclusion that the earlier undergraduate students are recruited into the laboratory, the more effective and involved they can become. Often, younger undergraduate students are overlooked for research positions due to their reduced level of technical knowledge and lack of laboratory experience. However, these same undergraduates generally have more free time and enthusiasm to devote to their research efforts and are more likely to continue working with the laboratory beyond their first semester. Many of the greatest contributions made to our laboratory research by undergraduates have come from those who were recruited at the sophomore or even freshman level and retained by the laboratory for multiple semesters.

The core strategy of our undergraduate research program is to impart a sense of ownership to the students, in the hopes that they then take a greater stake in their work and can make a more significant contribution to the research efforts of our laboratory. We try to accomplish this through a great variety of means, as different students may be drawn more strongly to one aspect or another. For instance, every undergraduate working in the laboratory is provided a laboratory notebook, a specified drawer in the laboratory to store their notebook and research materials, and a lab coat. Undergraduate researchers are also included in laboratory photographs, added to our contact list, and their names are listed on the laboratory website. In this way, the undergraduates are quickly encouraged to see themselves as full members of the laboratory.

Encouraging the undergraduates to receive course credit (usually via a technical elective course option, a senior thesis, or an honors thesis) and to participate in the departmental and universitywide structured undergraduate research programs is another excellent way to increase the 
students' sense of ownership of their research. Additional methods common to our laboratory include applying for university-sponsored, undergraduate-specific research grants to defray the cost of the experimental work; being required to write a project report and/or present a poster at the departmental level at the conclusion of the semester; and applying for departmental, college, university, or even nation-wide paper and presentation opportunities and awards. In particular, every undergraduate researcher is required to apply for UT's undergraduate research fellowship awards. In the process of writing the requisite research proposal, the students are forced to see the larger picture and understand the specific goals of their project at an earlier stage than is otherwise typical.

Once undergraduate students have been successfully integrated into the laboratory, the mentoring opportunities are abundant. An excellent practice is for the supervising professor to meet occasionally (1-2 times a semester) with both the undergraduate student and their graduate mentor to discuss their research progress. A substantial impact can also be made on their future through discussion of career goals and the opportunities they will have along the way. In our laboratory, we have seen again and again that these one-on-one interactions with the graduate student mentors and supervising professors can have a major impact on the level of effectiveness and the sense of project ownership of the undergraduate researcher. It has been our general experience as a laboratory that the more the undergraduate researchers are treated as full members of the research team, the more careful, productive, effective, and rewarding (both to them and to their mentors) their efforts become.

\section{Survey Methodology}

In determining the impact of undergraduate research on both undergraduate and graduate students, we surveyed four main groups of current and former students. The undergraduate researcher's perspective on their research experiences were obtained from two general groups of undergraduate students: undergraduate researchers and Peppas laboratory undergraduate researchers. The group defined as undergraduate researchers included UT undergraduate students in chemical engineering, biomedical engineering, and mechanical engineering not affiliated with the Peppas laboratory. Peppas laboratory undergraduate researchers included current and former undergraduate students who have performed research in the Peppas laboratory at both UT and Purdue University. The remaining two survey groups of current graduate students and Peppas laboratory alumni were surveyed in order to obtain the impact of undergraduate research on the graduate student mentors. Current graduate students consisted only of UT graduate students in chemical engineering and biomedical engineering. The Peppas laboratory alumni surveyed included doctoral degree graduates of both The University of Texas at Austin and Purdue University.

\section{Results and Discussion}

On the surface, the extent of the impact of this undergraduate research program is evident. Due in large part to the efforts of professor Peppas and his graduate students, more than 325 students have gone on to pursue higher degrees after completion of their baccalaureate. In addition, 38 of the 82 graduate students involved in this research program are now tenured or tenure-track faculty members at universities across the globe. These alumni indicate that some measure of 
their success is a result of their early experience mentoring undergraduate students in academic research endeavors. Furthermore, the research performed by these undergraduate students has led directly to the publication of 140 scholarly journal articles, submission of 43 conference abstracts, 5 patents, and more than 130 presentations at national scientific conferences ${ }^{9}$. Seventeen of these Peppas laboratory undergraduate researchers went on to become tenured or tenure-track faculty after completion of their doctoral degrees, which represents $30 \%$ of the total alumni from our laboratory that have eventually entered academic faculty positions. Thus, incorporating these undergraduates into our laboratory has had a long-term impact on the laboratory support system and the field of influence of the laboratory's research. An analysis based on laboratory records of the educational achievements of undergraduate researchers in our laboratory is presented in Table 1. The data is presented in 5-year groupings, with the exception of a 2-year period prior to the move from Purdue University to The University of Texas at Austin. With the assumption that a proportionate number of the 27 undergraduates from 20032008 that have not yet graduated will seek a higher degree, the fraction of undergraduates that have continued their education after receiving a baccalaureate has remained steady for the last two decades. Nearly 2 out of every 3 participants in our undergraduate research program have furthered their education. This data also shows a sharp decrease in the popularity of pursuing an MBA after graduation and the increasing tendency to seek a jurisprudence degree over just the last 15 years.

Table 1. Undergraduate research participation and their achieved higher degrees during the last 33 years in the laboratory of Nicholas A. Peppas'.

\begin{tabular}{cccccccc}
\hline \hline Period & Number & MS, PhD & MBA & MD & JD & Total & $\%$ \\
\hline $1976-1980$ & 72 & 13 & 15 & 3 & 1 & 32 & $44 \%$ \\
$1981-1985$ & 79 & 18 & 14 & 6 & 3 & 41 & $52 \%$ \\
$1986-1990$ & 93 & 24 & 29 & 9 & 3 & 65 & $70 \%$ \\
$1991-1995$ & 89 & 16 & 23 & 12 & 7 & 58 & $65 \%$ \\
$1996-2000$ & 78 & 27 & 9 & 8 & 6 & 50 & $64 \%$ \\
$2000-2002$ & 37 & 6 & 5 & 2 & 14 & 27 & $73 \%$ \\
$2003-2008$ & 78 & 22 & 4 & 8 & 11 & 45 & $58 \%$ \\
\hline Total & 526 & 125 & 99 & 58 & 45 & 327 & $62 \%$
\end{tabular}

Of these undergraduates, we attempted to survey 100 individuals and received 53 responses. In addition, we were able to gather 60 survey responses from undergraduates in engineering disciplines at UT (primarily chemical, biomedical, and mechanical) who were not associated with our laboratory. If we compare the statistics from Table 1 with the analogous data for the respondents of our surveys (Figure 1), we can see a distinct difference in the make-up of the entire population of the Peppas laboratory and the population we were able to sample. While the distribution of higher degree choices amongst the survey respondents is comparable, there is a much larger preference for baccalaureate and MBA degrees in the entire Peppas laboratory undergraduate researcher population than in those surveyed. One source of this trend could be the decreased ability to contact students from the earlier time spans, which tended to favor MBA and BS degrees to a greater extent. However, this may also indicate a greater likelihood of responding to the surveys amongst those students who pursued higher degrees, which is supported in part by the similarities between Figure 1(b) and (c). 


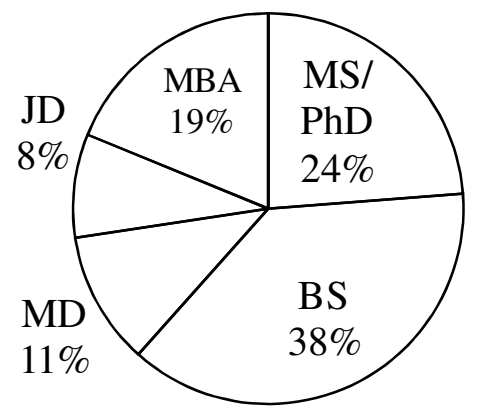

(a)

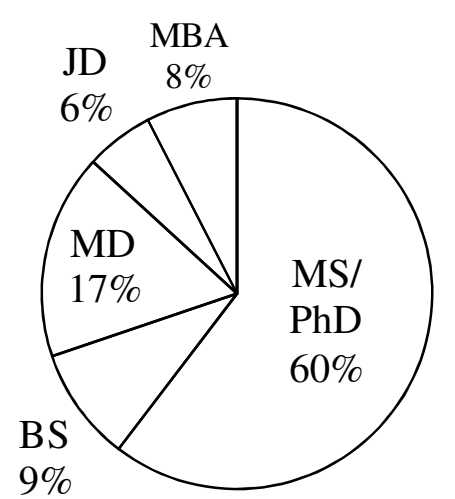

(b)

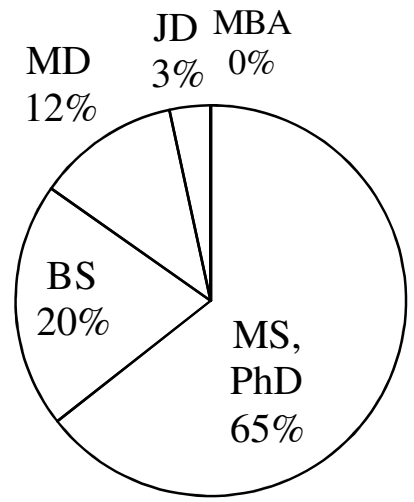

(c)

Figure 1. Distribution of ultimate or planned education levels of (a) the entire Peppas laboratory undergraduate population; $(b)$ the Peppas laboratory undergraduate researchers surveyed; and (c) other undergraduate researchers.

One key question we sought to address with these surveys was the extent to which participation in undergraduate research encourages students to pursue higher degrees. Of those surveyed, 75\% identified "determining interest in graduate school" as a motivating factor in their decision to participate in a research, with $47 \%$ of the Peppas laboratory undergraduate research respondents and $34 \%$ of the other undergraduate research respondents listing it as the most critical factor. The breakdown of the most critical factors for everyone surveyed is presented in Figure 2. It is interesting to note that though over half of all respondents mentioned course credit and $20 \%$ mentioned pay as influencing factors, very few students saw either as the primary factor in their decision to pursue research at the undergraduate level. The degree to which interest in graduate school motivated the undergraduate researchers who were surveyed indicates a general predisposition for graduate study in those participating in undergraduate research, which is

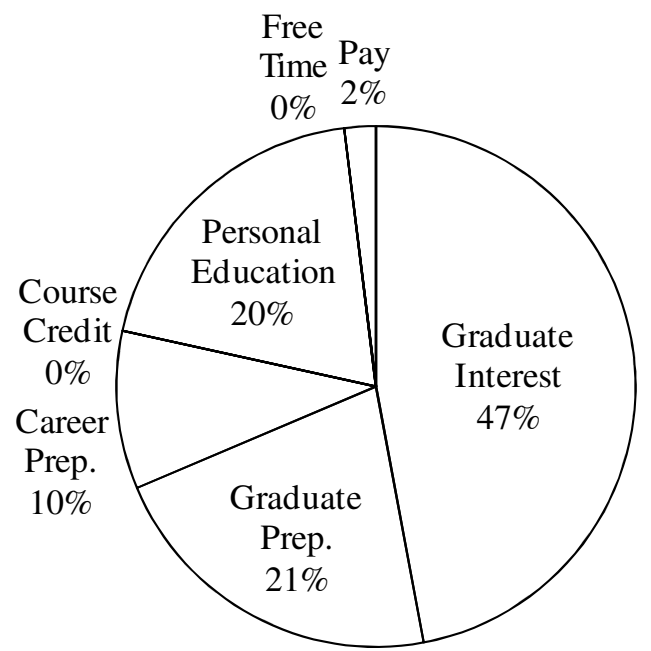

(a)

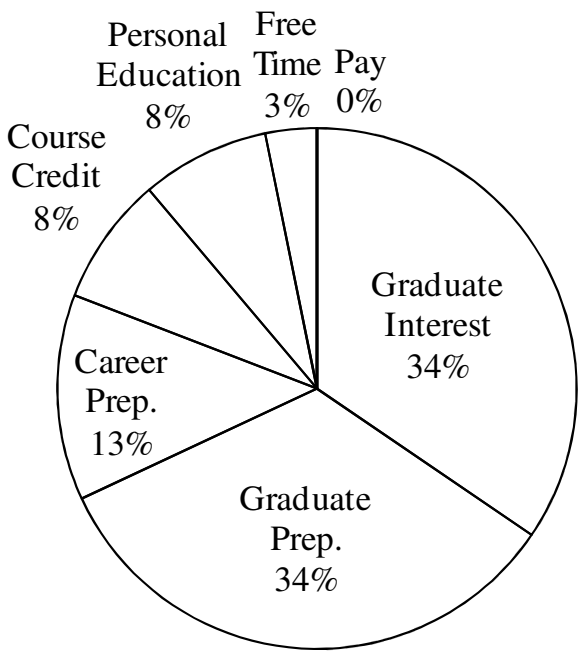

(b)

Figure 2. Primary motivating factors for participation in undergraduate research for $(a)$ the Peppas laboratory and (b) other engineering departments at UT. 
surely the case. However, our expectation is that the opportunity to investigate this interest in a higher degree is paramount in the transition from interest to enrollment, which is supported by the survey responses, as shown in Figure 3. Of those that participated in undergraduate research in the Peppas laboratory, $79 \%$ stated that their experience in the laboratory had a significant impact on their decision to attend graduate school with $98 \%$ of those then choosing to further their education. Additionally, $61 \%$ of undergraduate research participants responded that participation in undergraduate research had affected their decision to continue their education, with $78 \%$ of those then subsequently choosing to enroll in a higher degree program.

(a)

- Peppas Laboratory

$\square$ Other Undergraduate Researchers

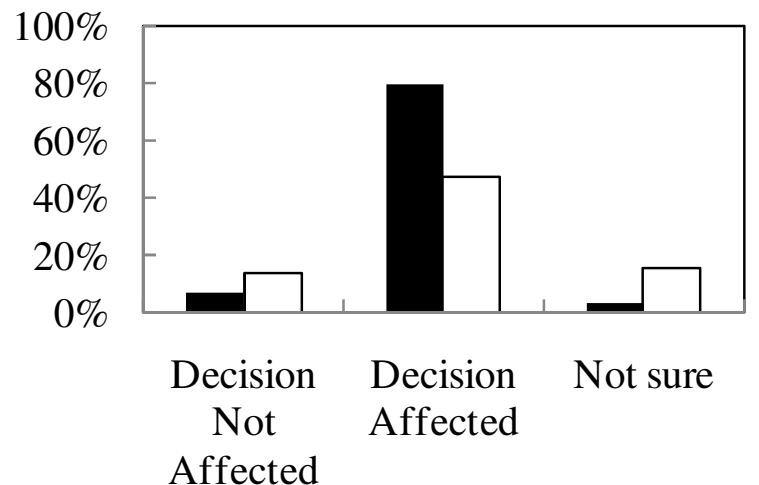

(b)
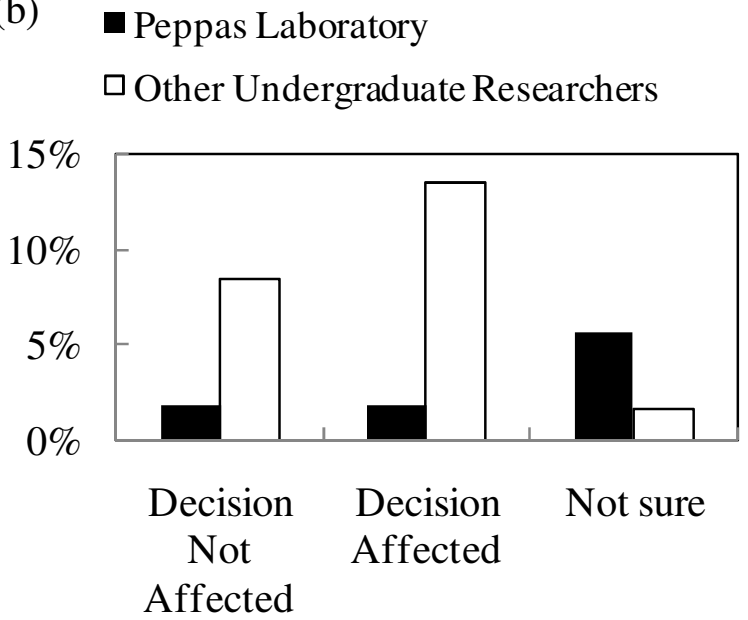

Figure 3. Impact of undergraduate research on (a) the decision to pursue a higher degree or (b) to finish with a baccalaureate in the Peppas laboratory undergraduate researchers compared to other undergraduate researchers.

In addition to impacting the decision on whether or not to continue one's education, participation in undergraduate research projects has a number of tangible, short-term, and long-term benefits. For example, $50 \%$ of Peppas laboratory undergraduate researchers and $38 \%$ of other undergraduate researchers responded that they received tangible benefits as a result of their research efforts, in the form of publications (47\%), abstracts (36\%), or monetary awards (17\%). These results, as well as the undergraduate research experience in general, have positive shortterm impacts on job and graduate program searches.

Furthermore, $89 \%$ of Peppas laboratory undergraduate researchers and $74 \%$ of other undergraduate researchers responded that their research efforts helped them develop critical thinking and problem solving skills that they could not have gained in a classroom. These skills not only enhance the quality of their undergraduate education, but also provide long-term educational and career benefits. Indeed, $89 \%$ of those who gained additional critical thinking and problem solving skills went on to say that their undergraduate research experience had a positive impact on the success of their careers and other long-term benefits (compared with 48\% of those who indicated they did not gain new critical thinking skills). This in turn correlated directly with the level of responsibility and project structure that the undergraduates were given in their research experience. Of those students who responded that they developed new critical thinking and problem solving skills and that they saw a long-term positive career benefit as a 
result of their undergraduate research, $91 \%$ had well-defined research projects (compared with $70 \%$ of those who indicated they did not develop new skills). These same respondents also indicated that on average they had a higher level of responsibility in the research process by a factor of 2.34 vs. 1.90 (on a scale of 1, minimal, to 3, high responsibility and involvement in the decision making process).

Because undergraduate researchers work alongside and are often mentored by graduate students, we were interested in determining the perspective of current graduate students at UT and alumni of the Peppas laboratory on the impact of undergraduate research on graduate students. We surveyed 58 graduate students in the Departments of Chemical Engineering and Biomedical Engineering at UT and 46 of the graduate alumni from this laboratory including alumni of both Purdue University and The University of Texas at Austin.

Survey results indicated that graduate students are involved in mentoring undergraduate researchers extensively, which suggests that undergraduate research may have an impact on a significant number of graduate students. To put this into perspective, $95 \%$ of current graduate students and $81 \%$ of Peppas laboratory alumni who responded to the survey had mentored or supervised undergraduate researchers. The number of current graduate students who are involved in the mentoring of undergraduate researchers is higher than we expected. It is a possibility that current students who have not worked with undergraduate researchers chose not to answer the survey questions. Nevertheless, in both the statistics obtained from both current graduate students and Peppas laboratory alumni, we do see graduate students frequently being involved in the mentoring of undergraduate researchers.

With this widespread involvement of graduate students in the work of undergraduate researchers, we also found that many graduate students work with undergraduate researchers participating in undergraduate research programs which encourage or offer incentives for undergraduate research. We found similar experiences between Peppas laboratory alumni and current graduate students which are displayed in Figure 4(a) and (b).

Of the Peppas laboratory alumni surveyed, 63\% worked with undergraduate researchers receiving course credit, which was somewhat higher than the $53 \%$ of current graduate students surveyed. In addition to working with undergraduate researchers receiving course credit, $53 \%$ of Peppas laboratory alumni worked with undergraduate researchers doing research to complete their bachelor's thesis compared to $11 \%$ of UT graduate students surveyed. Peppas laboratory alumni in comparison to current graduate students had less experience working with undergraduate researchers participating in university sponsored research programs (32\% vs. $66 \%$ ) and National Science Foundation Research Experience for Undergraduates (NSF-REU) (6\% vs. 23\%). Because the Peppas laboratory alumni survey included responses from alumni from 1976 through the present, many of whom graduated before the Boyer Commission report and the resulting formation of programs specifically designed to encourage undergraduate research, the discrepancy between current graduate students and Peppas laboratory alumni is not surprising. Based on the number of current graduate students who have mentored students participating in undergraduate research programs, we conclude that these programs positively influence the mentoring skills of graduate students, as they often play a significant role in selecting and advising the undergraduates they work with. 


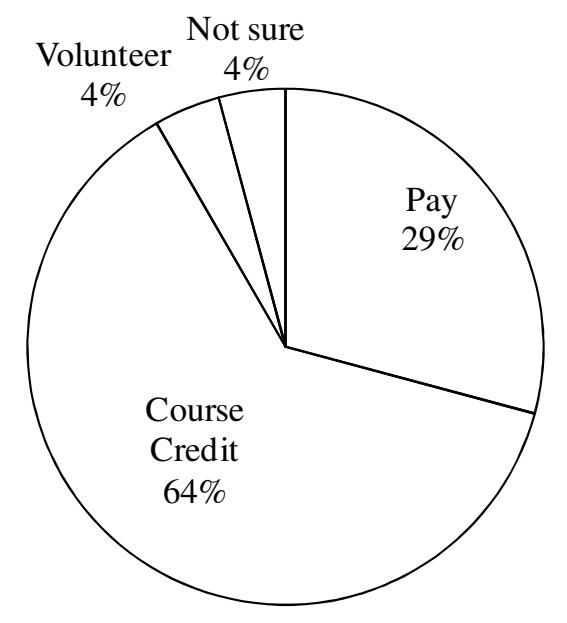

(a)

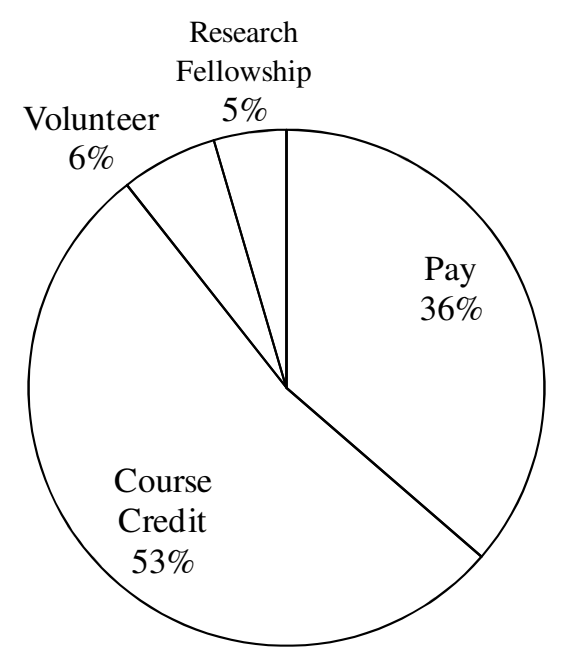

(b)

Figure 4. Graduate students who mentored undergraduates receiving incentives for research of (a) Peppas laboratory alumni and (b) current graduate students.

Overall, is undergraduate research beneficial to the graduate student? In short, yes, graduate students receive an added and apparent benefit from working with undergraduate researchers. The majority of Peppas laboratory alumni (85\%) and UT graduate students surveyed (71\%) responded that their graduate level education was enhanced by working with undergraduate researchers. Nearly $85 \%$ of the graduate students in both groups would recommend working with undergraduate researchers to other graduate students, which illustrates that these benefits may be immediate but also long-term.

In looking at the outcomes of graduate students working with undergraduate students, the majority of graduate students reported a tangible, successful outcome as a result of their collaboration with an undergraduate researcher. Surveys showed that $76 \%$ of Peppas laboratory alumni and over half $(51 \%)$ of current graduate students reported that the undergraduate researchers they worked with made a significant contribution to a publication, submission of an abstract, a monetary award, or a patent application related to their research.

While not all graduate students reported tangible outcomes from their experience with undergraduate researchers, many responded that there were intangible benefits which have immediate and long-term impacts on their development as students. Survey results from current graduate students show that experience with undergraduate researchers has short-term positive impacts on leadership, organizational, and mentoring skills. Responses from Peppas laboratory alumni confirm this and suggest that these benefits are lasting with the ability to impact careers. Peppas laboratory alumni reported that while mentoring undergraduate researchers did not typically impact their career path (80\%), over half (57\% of those surveyed) reported that their experience mentoring undergraduate researchers as graduate students helped them to succeed in their future career path.

Undergraduate research, therefore, benefits graduate students through research contributions and educational development which can ultimately impact their future success. 


\section{Programs Supporting Undergraduate Research}

The recruitment and retention of undergraduate researchers in our laboratory has been encouraged by many programs and systems at the University of Texas at Austin. The importance of established mechanisms of undergraduate support cannot be underestimated, and are a requirement for a successful undergraduate research program. Voluntary participation in research does not provide an immediate reward to the undergraduate student. The majority of undergraduate students participate in research to achieve longer-term career goals, such as determining their interest in graduate school, or to prepare themselves for independent research during graduate education, as demonstrated by our survey results. In contrast, the traditional undergraduate engineering education typically encourages a short-term view of learning. The majority of a student's time is spent in courses, which are typically designed on a semesterly or quarterly schedule - at the end of each term, the requirements end. The immediate demands of homeworks, exams, and projects may diminish the ability of a student to pursue longer-term objectives.

Considering this paradox, why do undergraduates participate in undergraduate research at all? Though some are able to act upon their individual personal motivation - based on our survey results, approximately $14 \%$ participate as volunteers - the vast majority ( $86 \%)$ receive a small incentive or reward for participation in undergraduate research. The incentives are typically not significant, but appear sufficient to encourage a substantially larger number of undergraduates to participate. Given this perspective, the intent of this section is to describe the support systems available at UT which encourage undergraduate participation in research. The Peppas laboratory has benefited from the majority of these programs, and it has enhanced the quality of projects we are able to provide to our students.

Students are introduced to research opportunities through a variety of mechanisms. Traditional routes are either through communication with fellow undergraduate students or through advisor encouragement. However at UT, there are established methods of communicating research opportunities and the benefits of engaging in research. The recent establishment of a College of Undergraduate Studies promises to coordinate many of these efforts university-wide. Within the College, there is an Office of Undergraduate Research. This office provides a website with a database of research opportunities, organizes a weekly information session, and provides one-onone advising. Additionally, the office provides assistance with research presentations and publications. Within specific engineering departments, such as biomedical engineering, emphasis on research opportunities exists as a formal component of undergraduate orientation and advising.

Within the engineering departments, two types of undergraduate researchers are typically encountered at UT - either those who had participated in research at their undergraduate institution, or at an outside institution through a research internship program. Approximately $85 \%$ of students who participated in programs external to the university participated in NSFREU programs. Within the university community, the programs available to engineering undergraduate students are detailed in Table 2. Earned course credit for participation in undergraduate research is available through assigned courses in individual engineering departments. Students typically may enroll in 1 to 3 credit hours, and present at a research poster 
session at the end of the semester. The administration of the poster session and course enrollment is provided by the specific departmental undergraduate coordinators. Though not an engineering-specific program, our laboratory has also benefited greatly through the Undergraduate Research Fellowship (URF) program, a university-wide initiative to support undergraduate research. This fellowship provides an award, up to $\$ 1000$, to fund research activities for a specific undergraduate researcher. The undergraduate must prepare a short proposal to apply for the award, and complete a final report. In our laboratory, graduate students mentor undergraduates in the preparation of their proposal to help them define achievable project goals and provide appropriate background information for context.

Finally, two programs focused on the improvement of under-represented minority participation in engineering also exist at UT. Both programs, Graduates Linked with Undergraduates in Engineering (GLUE) and Texas Research Experience (TREX) are primarily funded by corporate sponsorship, when available. Of the $21 \%$ of undergraduates who replied that they had participated in a formal program of undergraduate research, $46 \%$ had participated in an NSFREU, 46\% had participated in GLUE, and 8\% had participated in another type of internship.

Table 2: Undergraduate Research Programs at The University of Texas at Austin

\begin{tabular}{|c|c|c|c|c|c|c|}
\hline Program & $\begin{array}{c}\text { Year } \\
\text { Established }\end{array}$ & $\begin{array}{c}\text { Annual } \\
\text { Enrollment }\end{array}$ & $\begin{array}{l}\text { Primary } \\
\text { Funding } \\
\text { Source }\end{array}$ & $\begin{array}{l}\text { Funding } \\
\text { Amount }\end{array}$ & Metrics & Rewards \\
\hline URF* & 1996 & 233 & $\begin{array}{l}\text { The University } \\
\text { Co-operative } \\
\text { Society }\end{array}$ & $\sim \$ 215 \mathrm{k}$ & Final report & $\begin{array}{c}\text { Research } \\
\text { grant }\end{array}$ \\
\hline GLUE & 2003 & 24 & $\begin{array}{c}\text { Corporate } \\
\text { sponsors (not } \\
\text { available 2009) }\end{array}$ & $\begin{array}{l}\$ 0 \text { to } \\
\$ 12 \mathrm{k}\end{array}$ & None & $\begin{array}{l}\text { Course } \\
\text { credit }\end{array}$ \\
\hline TREX $^{10}$ & 1992 & $\sim 13$ & $\begin{array}{l}\text { Corporate } \\
\text { sponsors }\end{array}$ & $\sim \$ 40 \mathrm{k}$ & $\begin{array}{l}\text { Research plan, } \\
\text { progress reports, final } \\
\text { report, poster and } \\
\text { oral presentation }\end{array}$ & $\begin{array}{l}\$ 2600 \\
\text { annual } \\
\text { stipend }\end{array}$ \\
\hline $\begin{array}{l}\text { Course } \\
\text { Credit }\end{array}$ & $\begin{array}{l}\text { Variable by } \\
\text { department }\end{array}$ & 90 (BME) & $\begin{array}{c}\text { Individual } \\
\text { departments }\end{array}$ & NA & Poster session & $\begin{array}{l}\text { Course } \\
\text { credit }\end{array}$ \\
\hline
\end{tabular}

In addition to the programs specifically designed to increase undergraduate participation in research, there exist many UT programs which indirectly support research. These programs are also extensively engaged in by many undergraduates in the Peppas laboratory. For example, the college of engineering offers an Engineering Honor's Thesis. The student enrolls in a two semester course, completes research under the supervision of a faculty advisor, prepares a final thesis report, and presents the results of their research at a special thesis symposium. The university also has a unique dual degree program, called Plan II, which culminates in an honor's thesis. Our laboratory is familiar with the requirements of each of these programs and regularly mentors 2-3 engineering students annually who are completing these honor's thesis requirements.

The results of our laboratory's research program have been recognized through awards received by undergraduates. During the past three years, for instance, five exceptional undergraduates have been selected for various departmental, university-wide, and national awards. In 2006 and 
in 2008, Peppas laboratory undergraduates which were enrolled for course credit were selected as the best posters in the chemical engineering department's undergraduate poster session. In 2007, an undergraduate researcher received the first Undergraduate Research Award from the university's Senate of College Councils. This particular award is intended to encourage freshman participation in undergraduate research. A recent undergraduate won a $\$ 1000$ award at the 2007 poster competition of the Longhorn Research Week, a university-wide forum organized by the Associate Dean for Research Office. Finally, an undergraduate received a 2007 Undergraduate Research and Design Award from the Biomedical Engineering Society. These awards demonstrate our lab's commitment to advancing the opportunities for undergraduates to participate at a highly performing level in research.

\section{Conclusions}

In summary, when organized and managed properly, incorporating undergraduates into the research efforts of a laboratory can have meaningful and lasting impacts on the lives and careers of not only the undergraduate researchers, but also on their supervising professor and graduate student mentors. Undergraduate researchers can provide a long-term impact on the laboratory support system and the field of influence of the laboratory's research. Over the past 33 years, our laboratory has successfully run an effective undergraduate research program, based on the perspectives of those involved. This is not to say that incorporation of undergraduates into laboratory research efforts is universally a positive experience for every participant or that every undergraduate student will succeed given the proper structure and attention. The ultimate value of such an experience will depend primarily on the levels of dedication and effort of all involved.

We conclude that the keys to our laboratory's undergraduate research success are promoting a sense of ownership and involving the undergraduate researchers in well-defined projects, often with high levels of responsibility; encouraging, supporting, and utilizing structured undergraduate research programs on campus, including research for course credit or a senior/honors thesis and applying for research grants and awards; providing accountability to the undergraduate students by requiring project reports and poster presentations at the end of each semester; and perhaps most importantly, treating the undergraduates as research peers and providing time for one-on-one interactions and mentoring with both the graduate student mentors and the supervising professor. Additionally, we invite the reader to review a selection of the more than 65 comments we received from the survey respondents, which are presented in the Appendices. In the end, incorporating undergraduates into laboratory research efforts is a worthy pursuit, as a researcher's impact on the world of science and engineering can be multiplied countless times by educating and inspiring others to pursue similar paths.

\section{Acknowledgements}

The authors would like to thank Nicholas Peppas for the extensive information on our laboratory history. We would also like to thank Ana Dison, Lynda Gonzales, Jeff Hallock, Terrie Lear, Heidi Mallon and Kelly McQueary for information and assistance with survey distributions. 


\section{Bibliography}

1. Carnegie Foundation for the Advancement of Teaching, Carnegie Classifications Data File, (2008).

2. Boyer Commission on Educating Undergraduates in the Research University, "Reinventing undergraduate education: A blueprint for America's research universities," (1998).

3. Bauer KW, Bennett JS, "Alumni perceptions used to assess undergraduate research experience," J. High. Educ., 74(2), 210-230 (2003).

4. Kardash CM, "Evaluation of undergraduate research experience: Perceptions of undergraduate interns and their faculty mentors," J. Educ. Psychol., 92(1), 191-201 (2000).

5. Van der Spiegel, J., Santiago-Aviles, J., \& Zemel, J.N., "SUNFEST - research experience for undergraduates", FIE Annual Conference Proceedings, 1997, http://fie.engrng.pitt.edu/fie97.

6. Hathaway, R.S., Nagda, B.A., \& Gregerman, S.R., "The relationship of undergraduate research participation to graduate and professional education pursuit: an empirical study", Journal of College Student Development, Vol 43, 2002, pp. 614-631.

7. Peppas NA, "Student preparation for graduate school through undergraduate research," Chem. Eng. Educ., 15, 135-137 (1981).

8. "Massachusetts Institute of Technology Undergraduate Research Opportunities Program." Cited 2009; Available from: http://web.mit.edu/urop.

9. Peppas NA, Personal Communication (2008).

10. Ogilvie AM, "Texas Research Experience Program: A Model for Undergraduate Research Programs," Proc. WEPAN/NAMEPA Joint Conf., (2005).

\section{Appendix A: Selected Comments from Undergraduate Alumni of the Peppas Laboratory}

"A major reason for the positive nature of my comments was the wonderful mentorship of Dr. Peppas. One on one interactions of faculty with undergraduate students is unique, but this made all the difference. He taught me how to be a scientist."

"I felt that my undergraduate research experience prepared me very well for my graduate school career. It gave me skills I would not have developed in any class offered at UT and contacts that are very important to me. I feel that undergraduate research is invaluable for anyone thinking of pursuing higher education and should be advertised more to sophomores and juniors as a way to expand their horizons."

"I think that all of my undergraduate research experiences, especially that in the Peppas laboratory, was critical in my decision to continue to graduate school. I worked with a great graduate student, who thankfully allowed me to do more in the lab than just wash glassware, and thus helped me to gain insight into what graduate school would actually be like (as much as you can understand as an undergrad anyway). I also think that the laboratory advisor makes a large impact on future career decisions, as I do not think that I would have ended up where I am now without the interactions I had with my advisors. Overall, I think there are many factors that can influence future career decisions for undergraduate students, and not all are limited to simply performing the research; the interactions in the labs with other students and professors are equally as important as the experience you receive while performing/assisting with the research projects."

"Dr. Peppas did an excellent job of treating the undergraduate researchers (in my case, the honors program) like typical members of the laboratory. He met with us on a regular basis, as well as assigned us to a mentoring graduate student." 
"What I enjoyed most about my research experience was the interaction with graduate students. That is something that you can't get from the classroom or any other program I know of. I benefited a lot from talking with graduate students about their research, learning lab techniques and how equipment works, and getting advice on graduate school and the application process."

"I gained the experience I was seeking and a lot of confidence through publication and presentation of the work. I also gained a lifelong mentor in Dr Peppas which has been invaluable. Though I did not pursue a career in $\mathrm{R}$ and $\mathrm{D}$ the experience had significant positive influence. It was full time for a summer so I did not have the pressure of classes and could enjoy the experience more fully. If you have the chance to create such opportunities in the future I hope that you do so."

"As an undergraduate, this was a great opportunity to understand what really happens in a lab. It also gave me an opportunity to get to know many of my professors better because I was in the building so much more. I learned many things about proper lab procedure and got to know the graduate students working with Dr. Peppas. I would recommend undergraduate research for all students."

"I believe that no one should decide to go to graduate school without first researching as an undergraduate. Knowledge of what graduate programs are like is less prevalent than knowledge of undergraduate programs. However, during my research, I am able to interact with graduate students and see how the system works. Also, I believe there are certain skills that are needed in either industry or graduate school that are not taught in class, but can be learned through research experience as an undergraduate."

\section{Appendix B: Selected Comments from Graduate Alumni of the Peppas Laboratory}

"I think it is very person specific. There are some undergraduates who take ownership of their aspect of the project and really invest themselves in the research. Others are not as involved or interested, for several reasons. That level of interest/investment is probably the most important factor in the success of the undergraduate research effort, more so than GPA or future plans."

"Working with, supervising and mentoring undergraduate students was one of most fulfilling aspects of my graduate experience."

"Undergraduate researchers are an integral component to the graduate experience. They allow a graduate student the opportunity to create experimental plans that others can follow, assess other's abilities, and obtain good managerial skills. These components are not accessible without interacting with undergraduates. I feel these relationships provide good training for future career positions where these skills are needed--industry where one supervises a technician or academia where one supervises other graduate and undergraduate students."

"It was a great experience for me as an undergrad and they are very valuable workers if supervised correctly. It helped me determine my path into graduate school and has helped me become a better mentor, researcher and leader supervising them while in grad school." 
"I believe undergraduate research is beneficial for both the undergraduate student and the graduate researcher. For the researcher it allows them to mentor and coach, better organization skills, improves technical knowledge because you need to relay your message to the undergraduate, and improves leadership skills."

"I believe the success of the undergraduate research experience is dependent mostly on the particular undergraduate student. Both from my own experience and those around me, if the undergraduate is dedicated, inquisitive and hard-working, the overall impact on their own studies and their contribution to the mentor's work is significant. Otherwise, it is just another day at the office. At the same time, I think that all graduate students should have some experience mentoring undergraduate students, mainly because this is usually their most intimate mentoring experience before they go on teaching or mentoring people in their own laboratories and the more experience, the better mentors they will make."

"It was wonderful to have so many undergraduates involved in research at the time of my graduate work in the Peppas lab. I think it enriched my graduate experience enormously. I know that it was a huge time commitment for Nicholas, but it really showed that he cared about all his students, graduate and undergraduate." 